\title{
A new perspective on musculoskeletal disorders - emerging ergonomic risks in the European Union and Romania
}

\author{
Maria - Elena Boatca $^{1 *}$, Alexandra Coroian ${ }^{1}$, and Anca Draghici ${ }^{1}$ \\ ${ }^{1}$ Politehnica University of Timisoara, Faculty of Management in Production and Transportation, 14 \\ Remus Street, 300191, Timisoara, Romania
}

\begin{abstract}
According to the European Agency for Health and Safety at Work, changes in employment arrangements, new technologies and an increasing ageing population are key sources of emerging risks. New and emerging risks should be a major area of interest for every organisation, as a thorough risk prevention activity is key to high organisation efficiency and increased employee wellbeing. Musculoskeletal disorders (MSDs) are not a new risk category by themselves, but the changing characteristics of the work system generate new types of MSDs as a profession-related pathology (work-related MSDs). There is limited literature on this matter, hence the paper provides relevant insights and a new perspective on ergonomic risks and MSDs. Also, the paper presents a comparative analysis of ergonomic risks in the EU and Romania - based on secondary data - and identifies emerging risks in this category.
\end{abstract}

\section{MSDs remain a concerning health issue}

As per European Agency for Health and Safety at Work (EU-OSHA), one in three workers report negative effects of work on their health [1]. Even more concerning is the increasing prevalence of these disorders among young workers. As part of EU-OSHA efforts to raise awareness on the high prevalence of musculoskeletal disorders (MSDs), the agency published in 2020 the first results of its third edition of the European Survey of Enterprises on New and Emerging Risks (ESENER). Among the results of ESENER, a significant aspect is that prominent prevalence of MSDs as occupational risks despite efforts to reduce this risk category [2]. World Health Organisation (WHO) defines MSDs as a category of health problems of the locomotor apparatus, where the locomotor apparatus is understood as the system of bones, muscles, cartilage, ligaments and nerves. This category of disorders and related symptoms are grouped under the same umbrella, irrespective of their intensity (i.e., ranging from light, passing disorders to disabling illnesses) [3]. Nonetheless, EUOSHA and Eurostat statistics demonstrate that distribution of working population by age, gender and occupation witnessed changes in the past decade, primarily driven by technological, economic, social and health-related factors.

\footnotetext{
* Corresponding author : maria.boatca@student.upt.ro
} 
Taking into consideration the definition provided by the International Risk Governance Council, emerging risks are the category of risks (either new or already known) that become visible in new or unfamiliar conditions [4]. From this point of view, MSDs are a familiar category of risks, but the changing conditions of the working environment may transform them into emerging risks. The paper aims to develop this premise and prove that MSDs should be treated using a more comprehensive approach - both well-known and emerging risks. Obviously, not all MSDs can be treated as an emerging risk, but those connected to the new characteristics of work organisation and labour market should be regarded as potential emerging risks. The most prominent work characteristics that serve the scope of this paper are rising robotisation and work automation, ageing workforce and rising number of white-collar employees.

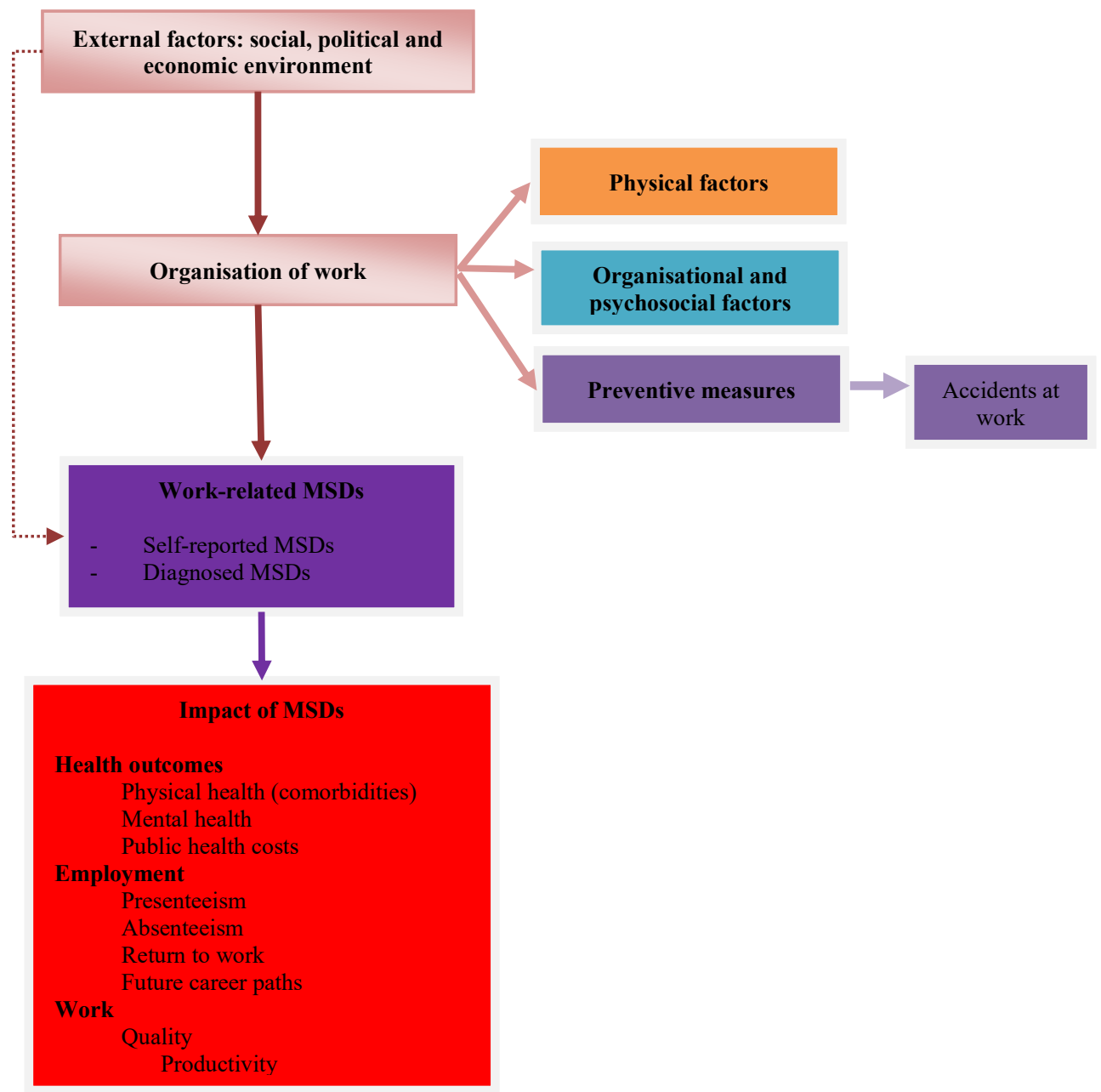

Fig. 1. Conceptual model - factors generating MSDs (adapted after [5])

Figure 1 presents a conceptual framework describing the factors that influence occurrence of MSDs and the impact of these disorders. Organisation of work, regarded as the sum of factors characterising physical and psychosocial work environments and preventive measures (whose absence leads to occupation accidents), is influenced by the external organisational environment, as well. This combination of elements represents the root cause of both self-reported and diagnosed work-related MSDs. Why MSDs are so important? 
Beside the health outcomes, translated into poor physical and mental health combined with costs for the organisation and the society, incidence of MSDs affects presenteeism and worker's capacity to properly perform work and even one's career path (on account of the necessity for professional reorientation in case of inability to further perform the work that generated the MSD).

Understanding the importance of preventing MSDs is the main reason for providing a new approach: treating work-related MSDs generated by the most recent changes in work system as emerging risks comes as a natural step.

In the past decade, EU-OSHA has been constantly making efforts to raise awareness on the severity of MSDs, generated by the increasing prevalence of such disorders combined with potential of leading to permanent work incapacity (disability). As part of these efforts, the Agency published reports and statistics that enable companies, employees and national occupational health and safety institutions across the EU to put all efforts towards minimising the impact of MSDs. Still, despite such efforts, statistics show rising incidence of this category of disorders. The reason behind it might be revealed by a thorough analysis of involved factors based on secondary data.

As of 2013, the most prevalent work-related disorder was the category of MSDs $(60 \%$ of the EU28 working population that reported work-related health issues) [1].

At EU level, table 1 indicates a rising percentage of workers reporting MSDs during 2010-2015, a continuation of the 2013 trend.

Table 1. Workers reporting MSDs at least once in the past year (source: [1])

\begin{tabular}{|c|c|c|}
\hline Geography & $\mathbf{2 0 1 0}$ & $\mathbf{2 0 1 5}$ \\
\hline EU-28 & $58 \%$ & $60 \%$ \\
\hline Romania & $69 \%$ & $62 \%$ \\
\hline
\end{tabular}

In continuation of the above details, section 2 provides an analysis of the main factors that come in support of the idea of treating MSDs as emerging risks in certain circumstances. Further, the paper presents a brief case study aiming to highlight research interest on MSDs in the context of Covid-19 pandemic, followed by discussion and conclusions.

\section{Analysis of main factors determining the emerging character of risks related to MSDs}

\subsection{Rising number of white-collar employees, prolonged sitting and telework}

A highly prevalent phenomenon that needs to be considered is the increasing number of white-collar employees, who typically use screens and sit for the whole work shift. This can be connected with the increasing prevalence of MSDs specific to prolonged sitting. As of 2017, 39\% of EU workers performed their work sitting [6]. There is evidence of connections between long hours typing (using a keyboard) and hand or arm MSDs, as well as identification of benefits when adopting ergonomic postures while using the computer and keyboard [7]. In general, MSDs caused by prolonged sitting in the case of computer users are maintaining a forced body position for a long time combined with repetitive movements, especially during typing [8]. Evidence of severe MSDs symptoms among computer users prove that this type of work should no longer be considered as "light work" [7]. This comes to enforce the necessity of treating MSDs linked to computer usage and prolonged sitting as an emerging risk. 
Nevertheless, this adds to the rising number of employees working outside of the office premises (remotely or in teleworking). In 2019, 43\% of the EU28 workforce (and $23 \%$ in Romania) worked outside of the office premises. 2020 marked a breakthrough, as the Covid-19 pandemic forced a large number of white-collar employees to shift from traditional office work to teleworking [9]. The pandemic context generated opportunities for creating new frameworks dedicated to identification of risks specific to industry 4.0 environments [10]. In this context, poor ergonomics increased prevalence of MSDs symptoms, transforming a renowned disorder into an emerging risk based on the changes in work arrangements. The unusual character of teleworking during the pandemic comes from a variety of social, economic and health-related factors (the pandemic changed behaviours and circumstances for the whole world). Along with prolonged sitting (which poses high ergonomic risks), the ergonomics of furniture used at home for teleworking was, in many cases, inadequate for the requirements of working at home for long periods of time [10].

An interesting perspective is offered by Boatca et al. in a cross-sectional study published in 2021: the pandemic negatively impacted health and wellbeing of respondents, with reports of moderate levels of pain in lower back and neck regions and unbearable pain in neck shoulders and elbows, despite efforts to organise a proper space for teleworking (including investments in furniture and devices) [11]. These results reinforce the necessity to address MSDs connected with prolonged sitting during telework as an urgent matter.

As per table 2, both in the EU and Romania the number of white-collar employees is increasing at a faster pace than the number of blue-collar employees. During 2011-2020, in EU-27, managers and professionals together accounted for a $23.4 \%$ increase, while technicians and associate professionals and clerical support professionals recorded, together, only a $5.9 \%$ increase. At the same time, in Romania, the number of technicians and associate professionals together with clerical support workers recorded a $25.7 \%$ decline during 2011-2020; moreover, the number of managers and professionals increased $11.2 \%$.

Table 2. Employees by gender and ISCO08 occupation (source: [12])

\begin{tabular}{|c|c|c|c|c|}
\hline \multicolumn{5}{|c|}{ EU-27 } \\
\hline \multirow{2}{*}{ Occupation } & \multirow{2}{*}{ Gender } & \multicolumn{3}{|c|}{ Number of employees (thousands) } \\
\hline & & 2011 & 2015 & 2020 \\
\hline \multirow{3}{*}{ Managers } & Total & $6,563.7$ & $6,468.0$ & $6,716.5$ \\
\hline & Males & $4,177.6$ & $4,193.1$ & $4,172.0$ \\
\hline & Females & $2,386.0$ & $2,274.9$ & $2,544.5$ \\
\hline \multirow{3}{*}{ Professionals } & Total & $25,978.9$ & $28,010.2$ & $33,436.1$ \\
\hline & Males & $11,713.3$ & $12,443.4$ & $14,623.7$ \\
\hline & Females & $14,265.6$ & $15,566.8$ & $18,812.4$ \\
\hline \multirow{3}{*}{$\begin{array}{c}\text { Technicians and associate } \\
\text { professionals }\end{array}$} & Total & $26,125.3$ & $27,491.1$ & $27,971.5$ \\
\hline & Males & $12,886.6$ & $13,228.6$ & $13,832.8$ \\
\hline & Females & $13,238.7$ & $14,262.5$ & $14,138.6$ \\
\hline \multirow{3}{*}{ Clerical support workers } & Total & $17,637.7$ & $17,500.8$ & $18,263.0$ \\
\hline & Males & $5,744.9$ & $5,714.3$ & $6,121.3$ \\
\hline & Females & $11,892.8$ & $11,786.4$ & $12,141.7$ \\
\hline \multicolumn{5}{|c|}{ Romania } \\
\hline \multirow{3}{*}{ Managers } & Total & 111.3 & 125.0 & 123.3 \\
\hline & Males & 71.5 & 79.9 & 73.4 \\
\hline & Females & 39.8 & 45.1 & 49.8 \\
\hline \multirow{3}{*}{ Professionals } & Total & $1,137.8$ & $1,216.4$ & $1,265.4$ \\
\hline & Males & 482.4 & 526.2 & 532.8 \\
\hline & Females & 655.4 & 690.2 & 732.6 \\
\hline \multirow{3}{*}{$\begin{array}{c}\text { Technicians and associate } \\
\text { professionals }\end{array}$} & Total & 564.4 & 480.6 & 533.9 \\
\hline & Males & 273.6 & 217.5 & 251.7 \\
\hline & Females & 290.8 & 263.1 & 282.2 \\
\hline
\end{tabular}




\begin{tabular}{|c|c|c|c|c|}
\hline \multirow{3}{*}{ Clerical support workers } & Total & 351.0 & 370.3 & 378.5 \\
\cline { 2 - 4 } & Males & 111.2 & 139.7 & 145.8 \\
\cline { 2 - 4 } & Females & 239.8 & 230.7 & 232.7 \\
\hline
\end{tabular}

Connecting the above information with the rising number of workers reporting MSDs, it is interesting to observe that prolonged sitting - known as a cause of MSDs symptoms may be one of the causes for rising incidence of such disorders.

European Working Conditions Survey also reveals that prolonged sitting is an increasing ergonomic risk in Romania: according to data in table 3, in 2015, young people were predominantly exposed to sitting regarded as ergonomic risk $(29 \%$ were sitting for almost all the work shift and $41 \%$ were exposed to this risk for $1 / 4$ to $3 / 4$ of the working shift) [13]. Also, more than half of the older workers (aged 50 and over) are sitting for long periods of time (at least $1 / 4$ and up to the whole working time) [13].

Table 3. Workers exposed to prolonged sitting in Romania, 2015 (source: [13])

\begin{tabular}{|c|c|c|c|c|}
\hline \multirow{2}{*}{ Proportion of working day } & \multicolumn{4}{|c|}{ Age gap (years) } \\
\cline { 2 - 5 } & Total & under 35 & $\mathbf{3 5 - 4 9}$ & $\begin{array}{c}\mathbf{5 0} \text { and } \\
\text { over }\end{array}$ \\
\hline (Almost) all of the time & $28 \%$ & $29 \%$ & $28 \%$ & $27 \%$ \\
\hline Between $1 / 4$ and $3 / 4$ of the time & $33 \%$ & $41 \%$ & $28 \%$ & $30 \%$ \\
\hline (Almost) never & $39 \%$ & $29 \%$ & $44 \%$ & $43 \%$ \\
\hline
\end{tabular}

Nevertheless, the 2019 edition of the European Survey of Enterprises on New and Emerging Risks (ESENER) has a section dedicated to emerging risks and their management. Along with psychosocial risks, digital technologies used at work are a separate category in this section. As per ESENER data, 86.6\% of EU working population and $74.1 \%$ of Romanian workers use a computer at a fix workplace [2]. In continuation of this trend, the survey reveals that $76.7 \%$ of EU workers and $87.9 \%$ of Romanian workers use mobile computer devices such as laptops, tablets and smartphones [2]. These high percentages should be an alarm bell for occupational health and safety specialists and ergonomists altogether, as the high prevalence of digital technologies in day-to-day work require special analysis and intensive preventive measures for reduction of MSDs caused by prolonged sitting, awkward postures (such as head bent forward to look at the screen for long periods of time) and repetitive movements during typing.

\subsection{Ageing workforce}

One more interesting aspect is the connection between ageing population and necessity to integrate older workers already suffering from MSDs. In 2019, employees aged 55 or more accounted for 26\% of the EU28 workforce, with an increase of 5pp during 2014-2019 [2]. Also, work-related MSDs record increasing prevalence for older workers, a result consistent with EU-OSHA statistics [2]. For the 55-64 years category, self-reported MSDs symptoms are 1.7 times more frequent than for the 25-34 years category, a proof of the increasing number of older workers and associated health concerns [14]. Advances in medical research, improved working conditions and rising life expectancy are factors that enable older workers to work at later stages in life; from this perspective, treating this category of workers differently is a requirement for reducing negative health outcomes and improve professional life quality.

Regarding the connection between ageing population and MSDs, the European Working Conditions Survey reveals interesting data. In Romania, 36\% of working population above 50 years old are exposed to vibrations from tools or machinery for more than a quarter of their working time [13]. For the same age group, in Romania, 22\% 
workers perform work involving tiring/painful postures for almost all of the working time, $5 \%$ lift loads or move people for more than a quarter of the working time, and $49 \%$ carry or move heavy loads for more than a quarter of the shift. Additionally, 39\% perform repetitive movements of hands/arms for almost all of the working time and $41 \%$ for $1 / 4$ to $3 / 4$ of the working time (this refers to Romanian workers aged over 50 years old).

In the end, [15] indicates a strong connection between exposure to physical and psychosocial risks and rising prevalence of MSDs.

\subsection{Unknown effects of industrial robotisation and automation}

Industrial manufacturing comes with a wide span of operations that cannot be automated; moreover, the automated operations require surveillance and limited human intervention (such as operating a control panel) regarded as activities with increasing frequency that replace previously manual tasks. Moreover, new production systems such as lean manufacturing come with their costs: research demonstrates that, despite its renowned benefits, lean manufacturing may generate MSDs on the back of faster work pace and little to no recovery time between operations [16]. Nonetheless, increasingly more researchers propose frameworks combining multiple fields of interest to reduce risks and improve system performance. For example, recent studies offer a proposal for a new methodological framework that combines ergonomics with Lean Six Sigma model [17].

However, work continues to involve manual material handling (such as lifting and carrying) for at least of $25 \%$ of the working day [18]. This adds to all the other ergonomic risks such as awkward postures (for example, bending, stretching, twisting). Research in automation and artificial intelligence made possible the creation of exoskeletons, as an aid for those operations that cannot be automated. Also, wearable robots (exoskeletons) should enable significant reduction of ergonomic risks [19]. However, exoskeletons developed for military and medical purposes are not suitable for industrial applications, hence projects such as "Robo-Mate" were dedicated exclusively for development of industrial solutions [19]. Robo-Mate, initially an EU-funded project became an industry solution: an exoskeleton that enables reduction of MSDs by supporting manual load handling (by taking over the load to reduce worker exposure to ergonomic risks) [20].

Another perspective comes from [21], demonstrating that human-robot collaboration may be the solution for those tasks that cannot be fully automated or replaced by robots. Human-robot collaboration is proposed as a solution to reduce MSDs caused by heavy load handling and high force exertion through interaction between a human and one or more robots to perform tasks with high ergonomic risks [21]. However, the novelty of such technologies requires further analysis on ergonomic risks in order to identify any emerging risks.

Other research demonstrates again the necessity to treat industrial automation with caution: by comparing the ergonomic risks of two assembly lines with different levels of automation, there has been found evidence that the semi-automated line did not allow possibility for rest while the non-automated one enabled more rest periods [22]. This, again, underlines the imperious requirement of identifying all emerging risks at the initial stage of implementing such technological advances. An example of proposed framework is [23], a model that includes human factors in design and simulation of new technologies implemented in smart factories, highlighting the need for further research on ergonomic implications on human workers.

As part of 2019 edition of ESENER, digital technologies at work are regarded as emerging risks, as shown in chapter 2. Statistical data on increasing use of robots and automation are the unbeatable proof of this industrial trend and its impact on individuals' wellbeing (particularly, emerging ergonomic risks). Table 4 contains ESENER results 
regarding digital technologies. Despite the low percentages, rising presence of digital technologies in work systems highlights the idea that robots and high-technology devices used at work is are here to stay.

Table 4. Digital technologies use in the workplace, EU-27 and Romania, 2019 (source: [2])

\begin{tabular}{|l|c|c|}
\hline \multicolumn{1}{|c|}{ Technology } & EU-27 & Romania \\
\hline Robots that interact with workers & $3.7 \%$ & $4 \%$ \\
\hline Machines/systems/computers determining the content or pace of work & $11.8 \%$ & $16.6 \%$ \\
\hline Machines/systems/computers monitoring workers' performance & $8.2 \%$ & $9 \%$ \\
\hline Wearable devices (smart watches, data glasses, embedded sensors) & $4.8 \%$ & $8.9 \%$ \\
\hline
\end{tabular}

\section{Case study: Research interest regarding MSDs during the Covid-19 pandemic}

The novelty of this research comes from the urge to understand the extent to which researchers and ergonomists regard MSDs as emerging risks due to their direct causal relationship with the Covid-19 pandemic. In order to easily obtain a generic overview on this matter, the authors performed an analysis of research published with regards to Covid19, MSDs and emerging risks in the pandemic context.

The methodology of the analysis consisted in performing searches of papers published during January 2020-September 2021 available on Web of Science, ScienceDirect and Scopus databases. The keywords used to perform the searches were combinations of the following terms: "Covid-19", "musculoskeletal disorder", "MSDs" and "emerging risk". The results obtained using each keyword combination were analysed for relevance to the theme of this paper, determining percentage of relevance using the following formula:

\section{Relevance $=$ number of papers relevant to the study / total number of papers}

By papers relevant to the study, the authors considered those papers studying the connection between the Covid-19 pandemic and MSDs, especially if MSDs were treated as emerging risks.

Results of this analysis are presented in table 5. There is a limited number of papers treating this subject, and from those available only a few papers study the connection between MSDs and the pandemic. This result highlights the necessity of paying more attention to new sources of risks leading to MSDs, as these are emerging risks that require special attention from researchers and practitioners.

Table 5. Search results from databases by number and relevance

\begin{tabular}{|l|l|c|c|}
\hline \multicolumn{1}{|c|}{ Database } & \multicolumn{1}{c|}{ Keywords } & No. of results & Relevance \\
\hline Web of Science & Covid-19, musculoskeletal disorder & 6 & $100 \%$ \\
\hline Web of Science & Covid-19, MSDs & 6 & $67 \%$ \\
\hline Web of Science & Covid-19, emerging risk & 14 & $7 \%$ \\
\hline ScienceDirect & Covid-19, musculoskeletal disorder & 104 & $20 \%$ \\
\hline ScienceDirect & Covid-19, MSDs & 492 & $0 \%$ \\
\hline ScienceDirect & Covid-19, emerging risk & 102 & $0 \%$ \\
\hline Scopus & Covid-19, musculoskeletal disorder & 32 & $100 \%$ \\
\hline Scopus & Covid-19, MSDs & 21 & $43 \%$ \\
\hline Scopus & Covid-19, emerging risk & 24 & $8 \%$ \\
\hline
\end{tabular}

Lastly, the authors generated a word cloud (see figure 2) using details of papers retrieved as search results from the three databases. "Musculoskeletal" is not a prominent 
word in this cloud, reinforcing the need to go more in-depth with research on MSDs as emerging risks during the Covid-19 pandemic.

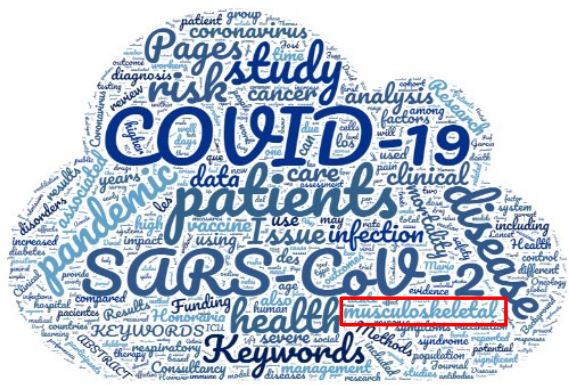

Fig. 2. Word cloud resulted from database searches of papers studying Covid-19 and MSDs

\section{Discussion}

Since the Covid-19 outbreak, the Ergonomics and Workplace Management Society in Romania has been making efforts to support students and workers in addressing all negative outcomes of teleworking. The most important result of these efforts is "Ergo@Home", an ergonomic guide for teleworking and telestudies. The guide provides useful insights from wellbeing, architecture and medical perspectives, supporting all interested parties in implementing valid solutions to emerging risks derived from new work and learning arrangements imposed by restrictions for reduction of infection with Covid-19 [24]. Regarding MSDs, the guide reinforces the rising prevalence of such disorders in connection with teleworking [24].

Recent research papers indicate rising prevalence of MSDs during the Covid-19 pandemic, drawing attention on the importance of adapted ergonomics and flexible solutions to the new work context. According to results presented in [25] - similar to other categories of workers - work-related MSDs among cardiac sonographers recorded aggravation and increased frequency during COVID-19 pandemic. Also, study on prevalence of MSDs among university staff demonstrates riding incidence of pain and disorders in knee, back and neck body areas [26]. These results reinforce the negative outcome of the pandemic on incidence of MSDs, adding to the already-presented aspects regarding teleworking (see section 2).

Another significant perspective that should be considered is that certain patients infected with Covid-19 reported symptoms of musculoskeletal pathologies (MSDs) [27], [28], [29]. Research suggests that MSDs occur during infection with Covid-19 as a direct consequence of the disorder, as well as a side effect of treatment with corticosteroids [30].

Moreover, prominence of MSDs as work-related disorders requires a change of paradigm: despite significant efforts to reduce this category of work-related disorders, they remain the most frequent category of risks at work. Therefore, new approaches to an old problem may be a revelation. Understanding the metamorphic character of MSDs and their visible character of an emerging risk category might be a turning point in the concentrated effort to reduce MSDs.

Regarding the case study in the previous section, similar research focused on highlighting interest on MSDs during the pandemic. However, the methodology was different, focusing on Google searches instead of analysing scientific papers. The results revealed a rising interest in seeking information regarding MSDs as compared to prepandemic period [31]. 


\section{Conclusions}

All the above aspects are the new reality of the work environments across the EU, being at the same time key sources of emerging risks. Despite that MSDs are not a novelty - on the contrary, MSDs remain one of the most prevalent categories of occupational disorders some of the MSDs are increasingly diagnosed as a work-related disorder [2].

As per ESENER 2019, from top three risks with the highest frequency among EU companies, two are ergonomic risks: repetitive hand or arm movements $(65 \%)$ and lifting/moving people or high loads (54\%) [2]. Both risks recorded growth from the 2014 edition of the survey, highlighting the need for accurate and more intense involvement in tackling ergonomic risks.

An important mention here is that MSDs are generally disorders with multiple causes. What makes an MSD to be considered a work-related disorder is the obvious connection between poor ergonomics in the workplace and occurrence of the symptoms after performing the specific tasks for a period of time, considering that the employee was healthy before being exposed to those ergonomic risks.

Considering the trends presented in this paper, MSDs should be treated as emerging risks when found in direct connection with the major changes occurring in the work system, as well as in connection with the Covid-19 pandemic.

\section{References}

1. Work-related musculoskeletal disorders: prevalence, costs and demographics in the EU [Online]. Available: https://osha.europa.eu/en/publications/msds-facts-and-figures-overview-prevalencecosts-and-demographics-msds-europe/view [Accessed 10.06.2021]

2. European Survey of Enterprises on New and Emerging Risks [Online]. Available: https://osha.europa.eu/ro/facts-and-figures/esener, [Accessed 15.06.2021]

3. https://www.who.int/occupational health/publications/oehmsd3.pdf [Accessed 9.09.2021]

4. https://theactuarymagazine.org/identifying-emerging-risks/, [Accessed 15.06.2021]

5. Workforce diversity and musculoskeletal disorders: review of facts and figures and [Online]. Available: https://osha.europa.eu/en/publications/preventing-musculoskeletal-disorders-diverseworkforce-risk-factors-women-migrants-and [Accessed 1.06.2021]

6. https://ec.europa.eu/eurostat/web/products-eurostat-news/-/DDN-20190305-1

7. F. Gerr, C. P. Monteilh, M. Marcus, J. occupational rehab., 16(3), 259-271 (2006)

8. M. Malinska, Medycyna pracy, 70(4), 511-522 (2019)

9. Teleworking during the Covid-19 pandemic and beyond. A practical guide, [Online]. Available: https://www.ilo.org/wcmsp5/groups/public/---ed protect/---protrav/--travail/documents/instructionalmaterial/wcms 751232.pdf [Accessed 2.07.2021]

10. A. Draghici, Changes and challenges of human systems management during and after the pandemic. IOS Press, (2020)

11. M.E. Boatca, A. Draghici, A. Gaureanu, MATEC Web of Conferences, 343, 11012 (2021)

12. Eurostat statistics on health and safety at work [Online]. Available: https://ec.europa.eu/eurostat/web/health/data [Accessed 10.06.2021]

13. European Working Conditions Survey [Online]. Available:
. https://www.eurofound.europa.eu/data/european-working-conditionssurvey?locale $=E N \&$ dataSource $=$ EWCS2015\&media $=$ png $\&$ width $=740 \&$ question $=$ determinants $\underline{\text { \&plot }=\text { heatMap\&countryGroup }=\text { linear\&subset }=\text { agecat } 3 \& \text { subsetValue }=3--50 \text {-and- }}$ over\&answer=1--3-or-more, [Accessed 1.07.2021]

14. F. Russo, C. Di Tecco, L. Fontana, G. Adamo, A. Papale, V. Denaro, S. Iavicoli, BMC Musculoskeletal Disorders, 21(1), 1-16 (2020)

15. J. C. Aldasoro, M. L. Cantonnet, J. safety research, 77, 277-287 (2021)

16. T. Koukoulaki, Applied ergonomics, 45(2), 198-212 (2014)

17. B. Cirjaliu, A. Mocan, M.E. Boatca, A. Draghici, Quality - Access to Success, 20(S1), 135 (2019) 
18. J. van der Vorm, J., R. Nugent, R., L. O'Sullivan, Procedia Manufacturing, 3, 1410-1417 (2015)

19. D. Ippolito, C. Constantinescu, C. A. Rusu, Procedia CIRP, 91, 243-248 (2020)

20. https://www.robo-mate.eu/documentation-photos-videos.html, [Accessed 1.07.2021]

21. Y. Y. Liau, K. Ryu, K, Procedia manufacturing, 51, 179-186 doi:10.1016/j.promfg.2020.10.026

22. F. Locks, G. Å. Hansson, H. C. Nogueira, H. Enquist, A. Holtermann, A.B. Oliveira, Int. J. Industrial Ergonomics, 67, 41-52 (2018)

23. W. P, Neumann, S. Winkelhaus, E. H. Grosse, C. H. Glock, Int. J. production economics, 233, s. 107992 (2021) doi:10.1016/j.ijpe.2020.107992

24. https://ergoworksociety.files.wordpress.com/2021/09/ergo40home.pdf [Accessed 7.09.2021]

25. J. Mazal, N. Kelly, T. Johnson, G. Rose, D. Phelan, J. American Society of Echocardiography, 34(5), 570 (2021)

26. A. Jafari-Nodoushan, G. Bagheri, Iranian J. Ergonomics, 8(3), 1-12 (2020)

27. R. Vaishya, V. K. Jain, K. P. Iyengar, J Clin Orthop Trauma, 17, 280-281 (2021)

28. A. Haleem, M. Javaid, R. Vaishya, A. Vaish, J Clin Orthop Trauma, 11(3), 498-499 (2020)

29. S. L. Ramani, J. Samet, J., C. K. Franz, C. Hsieh, C. Nguyen, C. Horbinski, S. Deshmukh, Skeletal Radiology, 1-11 (2021)

30. N. P. Disser, A. J. De Micheli, M. M. Schonk, M. A. Konnaris, A. N. Piacentini, D. L. Edon, ,.., C. L. Mendias, JBJS, 102(14), 1197-1204 (2020)

31. S. Kardeş, A. Erdem, H. Gürdal, Zeitschrift für Rheumatologie, 1-5 (2021) 